${ }^{[0000-0002-1753-416 \mathrm{X}]}$ А. Л. Концевой, к.т.н., доцент, e-mail: kontsev@xtf.kpi.ua

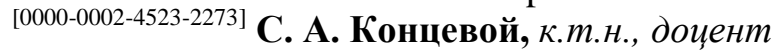

e-mail: serkon157@ukr.net

Київський політехнічний інститут імені Ігоря Сікорського

просп. Перемоги, 37, м. Київ, 03056, Україна

\title{
МОДЕЛЮВАННЯ ДВОПОТОКОВОГО ОЧИЩЕННЯ ГАЗУ ВІД ОКСИДУ КАРБОНУ (IV) РОЗЧИНОМ МОНОЕТАНОЛАМІНУ
}

Представлено алгоритм розрахунку матеріального і теплового балансів у середовищі Excel з варіюванням концентраційних параметрів по газу і розчину. Особливість розрахунку полягає у визначенні конщентрачії $\mathrm{CO}_{2}$ у газі після «грубого» очищення для отримання приблизно рівних витрат тонко і грубо регенерованого розчинів в абсорбері. Апроксимовано залежності рівноважного париіального тиску $\mathrm{CO}_{2}$ над розчином моноетаноламіну відповідно до ступеня карбонізачії, концентрації розчину та температури. Числовим інтегруванням розраховано кількість секиій у двосекиійному тарілчастому абсорбері.

Ключові слова: технологічний газ, оксид карбону (IV), моноетаноламін, кінетика і термодинаміка абсорбиії, тарілчастий абсорбер.

Вступ. Для отримання аміаку необхідно реалізувати кілька послідовних стадій виробництва технологічного газу. Одна 3 цих стадій полягає в очищенні технологічного газу від оксиду карбону (IV) абсорбційними методами, насамперед, розчином моноетаноламіну (одноі двопотокові схеми для потужності за аміаком 600 і 1360 т/добу, відповідно) або активованим гарячим розчином поташу (двопотокова схема). Хімізм очищення і порівняльний аналіз методів очищення достатньо повно надано в роботах [1-3]. Перспективним для українських виробництв $\epsilon$ метод очищення активованим розчином метилдіетаноламіну $[4,5]$.

Як об'єкт моделювання нами вибрана двопотокова схема очищення технологічного газу від $\mathrm{CO}_{2}$ розчином моноетаноламіну (MEA) 3 регенерацією відпрацьованого розчину у двох паралельно працюючих регенераторах-рекуператорах [6-8]. Особливість цієї схеми полягає у вимозі підтримувати приблизно однакові витрати тонко і грубо регенерованого розчину. Запропонований нами алгоритм значно відрізняється від розрахунку [9] за змістом і обсягом.

Мета роботи: розробка алгоритму і виконання багатоваріантних матеріальних, теплових і конструктивних розрахунків у середовищі Excel, що враховують коливання технологічного режиму за температурою, концентраціями газової і рідкої фаз у різних точках абсорбера.

(C) А. Л. Концевой, С. А. Концевой, 2019 DOI: 10.24025/2306-4412.3.2019.176874
Вихідні дані. За нашим алгоритмом для двопотокової схеми очищення газу продуктивністю за аміаком 1360 т/добу розраховано матеріальні, теплові баланси абсорбції та тарілчастий абсорбер $з$ наступними вихідними даними. Витрата конвертованого газу, що подається на очищення, $\mathrm{V}_{\text {к.г. }}=206000 \mathrm{~m}^{3} /$ год. Температура MEA на вході Твх $=313 \mathrm{~K}$. Концентрація МЕА на вході в абсорбер $\mathrm{C}_{\mathrm{MEA}}=20 \%$ мас. Кінцева концентрація $\mathrm{CO}_{2}$ $\mathrm{W \kappa}\left(\mathrm{CO}_{2}\right)=0,01 \%$. Тиск в абсорбері Рабс $=28$ атм. Концентрація компонентів у вихідній сухій газовій суміші, \% об.: $\mathrm{W}\left(\mathrm{CO}_{2}\right)=17,36 ; \mathrm{W}(\mathrm{CO})=0,5 ; \mathrm{W}\left(\mathrm{H}_{2}\right)=61,64$; $\mathrm{W}\left(\mathrm{CH}_{4}\right)=0,3 ; \mathrm{W}\left(\mathrm{N}_{2}\right)=19,95 ; \mathrm{W}(\mathrm{Ar})=0,25$. Ступінь карбонізації розчину МЕА, кмоль $\mathrm{CO}_{2} /$ кмоль MEA: на вході на стадію «тонкого» очищення $\alpha_{2 в}=0,1$; на виході зі стадії $\alpha_{2 н}=0,35$; на вході на стадію «грубого» очищення $\alpha_{1 \mathrm{~s}}=0,35$; на виході $\alpha_{1 н}=0,67$. Вміст $\mathrm{CO}_{2}$ на виході зі стадій, \% об.: «грубого» очищення, $\mathrm{c}\left(\mathrm{CO}_{2}\right)_{1}$ - невідоме і підібрано багатоваріантним розрахунком значення 5,64; «тонкого» очищення, $\mathrm{c}\left(\mathrm{CO}_{2}\right)_{2}=0,01$.

Розрахунок матеріального балансу. Далі надано алгоритм розрахунків і таблиці матеріального балансу у різних точках абсорбера $з$ урахуванням розчинності компонентів газової суміші у розчині. Таблиця 1 містить дані для подальших розрахунків. 
Таблиця 1 - Склад вихідного сухого конвертованого газу

\begin{tabular}{|l|c|c|c|c|}
\hline \multicolumn{1}{|c|}{ Компонент } & м ${ }^{3} /$ год & \% об. & кг/год & \% мас. \\
\hline $\mathrm{H}_{2}$ & 126978,4 & 61,64 & 11337,36 & 8,361 \\
\hline $\mathrm{N}_{2}$ & 41097 & 19,95 & 51371,25 & 37,884 \\
\hline $\mathrm{CO}_{2}$ & 35761,6 & 17,36 & 70246 & 51,803 \\
\hline $\mathrm{CO}$ & 1030 & 0,5 & 1287,5 & 0,949 \\
\hline $\mathrm{Ar}$ & 515 & 0,25 & 919,6429 & 0,678 \\
\hline $\mathrm{CH}_{4}$ & 618 & 0,3 & 441,4286 & 0,326 \\
\hline Всього & 206000 & 100 & 135603,2 & 100 \\
\hline
\end{tabular}

Витрата $\mathrm{CO}_{2} 3$ газом після стадії «грубого» очищення $\mathrm{V}(\mathrm{CO} 2)_{1}$, нм$^{3} /$ год:

$$
\begin{aligned}
& V\left(\mathrm{CO}_{2}\right)_{1}=\frac{c\left(\mathrm{CO}_{2}\right)_{1} \cdot V_{\text {k.2. }}-V\left(\mathrm{CO}_{2}\right) \cdot c\left(\mathrm{CO}_{2}\right)_{1}}{100-c\left(\mathrm{CO}_{2}\right)_{1}}= \\
& =\frac{5,64 \cdot 206000-35761,6 \cdot 5,64}{100-5,64}=10175,3,
\end{aligned}
$$

масова витрата, кг/год:

$$
\begin{aligned}
& m\left(C_{2}\right)_{1}=V\left(C O_{2}\right)_{1} \cdot \rho\left(C O_{2}\right)= \\
& =10175,3 \cdot 1,964=19987,3 .
\end{aligned}
$$

Витрата $\mathrm{CO}_{2}$ у конвертованому газі після стадії «тонкого» очищення, $\mathrm{M}^{3} /$ год:

$V\left(\mathrm{CO}_{2}\right)_{2}=\frac{c\left(\mathrm{CO}_{2}\right)_{2} \cdot V_{\text {k.2. }}-\mathrm{V}\left(\mathrm{CO}_{2}\right) \cdot c\left(\mathrm{CO}_{2}\right)_{2}}{100-c\left(\mathrm{CO}_{2}\right)_{2}}=$

$=\frac{0,01 \cdot 206000-35761,6 \cdot 0,01}{100-0,01}=17,01$,

масова витрата, кг/год:

$m\left(\mathrm{CO}_{2}\right)_{2}=V\left(\mathrm{CO}_{2}\right)_{2} \cdot \rho\left(\mathrm{CO}_{2}\right)=$

$=17,01 \cdot 1,964=33,41$. глинає:

На стадії «тонкого» очищення МЕА по-

$\alpha\left(\mathrm{CO}_{2}\right)=\alpha_{2 H}-\alpha_{2 \beta}=$

$=0,35-0,1=0,25$ кмоль / кмольМЕА,

$n\left(\mathrm{CO}_{2}\right)=\alpha\left(\mathrm{CO}_{2}\right) \cdot M\left(\mathrm{CO}_{2}\right)=$

$=0,25 \cdot 44=11,00$ кг/ кмольМЕА.

Витрата абсорбованого $\mathrm{CO}_{2}$ у верхній секції дорівнює, кг/год:

$m\left(\mathrm{CO}_{2}\right)=m\left(\mathrm{CO}_{2}\right)_{1}-m\left(\mathrm{CO}_{2}\right)_{2}=$

$=19987,3-33,41=19953,89$.

Для досягнення необхідного ступеня очищення необхідного тонко регенерованого MEA:

(C) А. Л. Концевой, С. А. Концевой, 2019 DOI: 10.24025/2306-4412.3.2019.176874
$n(\mathrm{MEA})=\frac{m\left(\mathrm{CO}_{2}\right)}{n\left(\mathrm{CO}_{2}\right)}=$

$=\frac{19953,89}{11}=1814$ кмоль $/$ год ,

$m(M E A)_{m . p .}=n(M E A) \cdot M(M E A)=$

$=1814 \cdot 61=110653 \mathrm{\kappa г} /$ год.

Отже, витрати чистого 20 \%-го розчину MEA і води становлять, відповідно, кг/год:

$m(M E A)_{p-\mu y} m \cdot p=\frac{m(M E A)_{m . p .} \cdot 100}{c(M E A)}=$

$=\frac{110653 \cdot 100}{20}=553264$.

$m\left(H_{2} O\right)_{m . p .}=m(M E A)_{p-n y ~ m . p}-m(M E A)_{m . p .}=$

$=553264-110653=442611$.

Кількість $\mathrm{CO}_{2}$ у розчині MEA на вході стадії «тонкого» очищення:

$n\left(\mathrm{CO}_{2}\right)_{p-H y}=\alpha_{2 \varepsilon} \cdot n(M E A)=$

$=0,1 \cdot 1814=181,4$ кмоль $\mathrm{CO}_{2} /$ год,

$m\left(\mathrm{CO}_{2}\right)_{m . p .}=n\left(\mathrm{CO}_{2}\right) \cdot M\left(\mathrm{CO}_{2}\right)=$

$=181,4 \cdot 44=7981,5 \kappa 2 \mathrm{CO}_{2} /$ год.

У подальших конструктивних розрахунках абсорбера практична витрата вихідного тонко регенерованого розчину виражена як, кг/год:

$\mathrm{L}_{2}=m(M E A)_{p-H y m . p}+m\left(C \mathrm{O}_{2}\right)_{m . p .}=$

$=553264+7981,5=561246,5$.

На стадії «грубого» очищення 1 кмоль MEA, що є сумішшю розчину після «тонкого» очищення і вихідного грубо регенерованого розчину (обидва потоки мають характеристики грубо регенерованого розчину - однакові ступені карбонізації), поглинає: 
$\alpha\left(\mathrm{CO}_{2}\right)=\alpha_{1 н}-\alpha_{1 в}=$

$=0,67-0,35=0,32$ кмоль / кмольМЕA,

$n\left(\mathrm{CO}_{2}\right)=\alpha\left(\mathrm{CO}_{2}\right) \cdot M\left(\mathrm{CO}_{2}\right)=$

$=0,32 \cdot 44=14,08$ кг / кмольМЕА.

Кількість $\mathrm{CO}_{2}$, яку необхідно видалити на стадії «грубого» очищення:

$m\left(\mathrm{CO}_{2}\right)_{p 1}=m\left(\mathrm{CO}_{2}\right)_{\text {nоч }}-m\left(\mathrm{CO}_{2}\right)_{1}=$

$=70246-19987,3=50258,7 \kappa 2 /$ год.

$\left(m\left(\mathrm{CO}_{2}\right)_{\text {поч }}-\right.$ див. табл. 1).

$V\left(\mathrm{CO}_{2}\right)_{p 1}=\frac{m\left(\mathrm{CO}_{2}\right)_{p 1}}{44} \cdot 22.4=$

$=\frac{50258,7}{44} \cdot 22,4=25586,3 \mu^{3} /$ год.

Отже, для досягнення необхідного ступеня очищення необхідно:

$n(M E A)=\frac{m\left(\mathrm{CO}_{2}\right)_{1 p}}{n\left(\mathrm{CO}_{2}\right)}=$

$=\frac{50258,7}{14,08}=3569,5$ кмоль $/$ год,

$m(M E A)_{\text {г.p. }}=n(M E A) \cdot M(M E A)=$

$=3569,5 \cdot 61=217740 \kappa 2 /$ год.

Витрата чистого 20 \%-го розчину грубо регенерованого розчину МЕА становить, кг/год:

$m(M E A)_{p-\mu y \text { z.p. }}=\frac{m(M E A) \cdot 100}{c(M E A)}=$

$=\frac{217740 \cdot 100}{20}=1088701$.

Витрата води у вихідному розчині, кг/год:

$m\left(\mathrm{H}_{2} \mathrm{O}\right)_{\text {г.p. }}=m(M E A)_{p-\mu y ~ г . p .}-m(M E A)_{\text {г.p. }}=$

$=1088701-217740=870961$.

Кількість $\mathrm{CO}_{2}$, що міститься у розчині МЕА:

$n\left(\mathrm{CO}_{2}\right)_{\text {г. } p}=\alpha_{2} \cdot n(M E A)=$

$=0,35 \cdot 3569,5=1249,3$ кмоль $\mathrm{CO}_{2} /$ год,

$m\left(\mathrm{CO}_{2}\right)_{\text {г.p }}=n\left(\mathrm{CO}_{2}\right)_{\text {г.p. }} \cdot M\left(\mathrm{CO}_{2}\right)=$

$=1249,3 \cdot 44=54970 \kappa 2 \mathrm{CO}_{2} /$ год

У подальших конструктивних розрахунках абсорбера загальна кількість грубо регенерованого розчину (зі ступенем карбонізації $0,35)$ на зрошення нижньої секції абсорбера 3 урахуванням $\mathrm{CO}_{2}$, абсорбованого при перебігу тонкого очищення, виражена наступним рівнянням, кг/год:

$\mathrm{L}_{1}=m(M E A)_{p-\mu y ~ z . p .}+m\left(C O_{2}\right)_{\text {г.p }}=$

$=1088701+54970=1143671$.

В останньому розрахунку у першому наближенні не враховано незначні витрати компонентів конвертованого газу, абсорбованих на стадії тонкого очищення. Отже, витрата саме грубо регенерованого потоку, що подається 3 регенератора, дорівнює різниці витрат розчину на вході на грубе очищення i розчину на виході з тонкого очищення, кг/год: $\mathrm{L}=\mathrm{L}_{1}-\left(\mathrm{L}_{2}+m\left(\mathrm{CO}_{2}\right)\right)=$ $=1143671-(561246,5+19953,89)=562470,6$.

Досягнуто приблизну рівність витрати тонко і грубо регенерованого розчинів в абcорбер: $\mathrm{L} \approx \mathrm{L}_{2}$.

Розрахунок фізичної абсорбції компонентів газу базується на їх розчинності SI у воді за атмосферного тиску i температури $\mathrm{t}=\mathrm{T}-273=313-273=40^{\circ} \mathrm{C}, \mathrm{M}^{3} / \mathrm{M}^{3}$ :

водень $\mathrm{SH}=0,02-0,0001 \cdot \mathrm{t}$;

азот $\mathrm{SN}=0,022-0,0003 \cdot \mathrm{t}$; оксид карбону (II) $\mathrm{SCO}=0,032-0,0004 \cdot t$; аргон $\mathrm{SA}=0,041-0.0004 \cdot \mathrm{t}$; метан $\mathrm{SM}=0,034-0,0002 \cdot \mathrm{t}$.

На стадії «грубого» очищення поглинається водою (концентрації компонентів $c(I)$ відповідають даним таблиці $1, \%$ об.), м $^{3} /$ год: водню

$V\left(H_{2}\right)_{p 1}=\frac{S H \cdot P \cdot c\left(H_{2}\right) \cdot V\left(H_{2} O\right)}{100}=240.5$,

де $\mathrm{V}(\mathrm{H} 2 \mathrm{O})=m\left(\mathrm{H}_{2} \mathrm{O}\right)_{\text {г.р. }} / 1000, \mathrm{M}^{3} /$ год .

Аналогічні розрахунки для азоту, оксиду карбону (II), аргону і метану. Результати цих розрахунків враховано у таблиці 2.

Додатково на стадії «тонкого» очищення поглинається (концентрації c(I) 2 відповідають даним таблиці 2, \%об.), м³/год: водню

$V\left(\mathrm{H}_{2}\right)_{2 p}=\frac{S H \cdot P \cdot c\left(\mathrm{H}_{2}\right)_{2} \cdot V\left(\mathrm{H}_{2} \mathrm{O}\right)_{2}}{100}=139,5$, де $V\left(\mathrm{H}_{2} \mathrm{O}\right)_{2}=m\left(\mathrm{H}_{2} \mathrm{O}\right)_{m . p .} / 1000, \mathrm{M}^{3} /$ год.

Аналогічно для азоту, оксиду карбону (II), аргону і метану. Результати розрахунків враховано у таблиці 3. 
Таблиця 2 - Склад сухого конвертованого газу після стадії «грубого» очищення

\begin{tabular}{|c|c|c|c|c|}
\hline Компонент & м$^{3} /$ год & \% об. & кг/год & \% мас. \\
\hline $\mathrm{H}_{2}$ & 126737,9 & 70,36 & 11315,9 & 13,27 \\
\hline $\mathrm{N}_{2}$ & 41048,4 & 22,79 & 51310,4 & 60,18 \\
\hline $\mathrm{CO}_{2}$ & 10175,3 & 5,64 & 19987,3 & 23,44 \\
\hline $\mathrm{CO}$ & 1028,0 & 0,57 & 1285,1 & 1,51 \\
\hline $\mathrm{Ar}$ & 513,5 & 0,29 & 916,9 & 1,08 \\
\hline $\mathrm{CH}_{4}$ & 616,1 & 0,34 & 440,1 & 0,52 \\
\hline Всього & 180119,2 & 100 & 85255,6 & 100 \\
\hline
\end{tabular}

Таблиця 3 - Склад сухого конвертованого газу після стадії «тонкого» очищення

\begin{tabular}{|c|c|c|c|c|}
\hline Компонент & м $^{3}$ год & \% об. & кг/год & \% мас. \\
\hline $\mathrm{H}_{2}$ & 126598,4 & 74,56 & 11303,4 & 17,32 \\
\hline $\mathrm{N}_{2}$ & 41020,1 & 24,16 & 51275,1 & 78,58 \\
\hline $\mathrm{CO}_{2}$ & 17,0 & 0,01 & 33,4 & 0,05 \\
\hline $\mathrm{CO}$ & 1026,9 & 0,60 & 1283,6 & 1,97 \\
\hline $\mathrm{Ar}$ & 512,6 & 0,30 & 915,3 & 1,40 \\
\hline $\mathrm{CH}_{4}$ & 615,0 & 0,36 & 439,3 & 0,67 \\
\hline Всього & 169790,0 & 100 & 65250,3 & 100 \\
\hline \multicolumn{4}{|r|}{} \\
\hline
\end{tabular}

У таблицях 4 і 5 умовно не враховано хімічну взаємодію $\mathrm{CO}_{2} 3$ MEA $з$ утворенням карбонатів і гідрокарбонатів. Кількість оксиду карбону (IV) у розчині надається у вигляді окремої статті. Саме тому концентрація MEA у вихідному розчині не дорівнює $20 \%$ - при реалізації циклічного процесу за МЕА у робочому розчині завжди наявний $\mathrm{CO}_{2}$ у формі карбонату.

Таблиця 4 - Матеріальний баланс процесу «тонкого» очищення по розчину

\begin{tabular}{|c|c|c|c|r|r|}
\hline \multicolumn{2}{|c|}{ Надходження МЕА } & \multicolumn{3}{c|}{ Витрата МЕА } \\
\hline Компонент & кг/год & \% мас. & Компонент & кг/год & $\%$ мас. \\
\hline Розчин МЕА, в т.ч. & 561246,6 & 100 & Розчин МЕА, в т.ч. & 581251,94 & 100 \\
\hline МЕА & 110653,0 & 19,72 & MEA & 110653,01 & 19,0370 \\
\hline $\mathrm{H}_{2} \mathrm{O}$ & 442612,0 & 78,86 & $\mathrm{H}_{2} \mathrm{O}$ & 442612,04 & 76,1481 \\
\hline $\mathrm{CO}_{2}$ & 7981,5 & 1,42 & $\mathrm{CO}_{2}$ & 27935,35 & 4,8061 \\
\hline & & & $\mathrm{H}_{2}$ & 12,46 & 0,0021 \\
\hline & & & $\mathrm{N}_{2}$ & 35,30 & 0,0061 \\
\hline & & & $\mathrm{CO}$ & 1,41 & 0,0002 \\
\hline & & & $\mathrm{Ar}$ & 1,58 & 0,0003 \\
\hline & & & $\mathrm{CH}_{4}$ & 0,79 & 0,0001 \\
\hline
\end{tabular}

Таблиця 5 - Матеріальний баланс процесу «грубого» очищення по розчину

\begin{tabular}{|c|c|c|c|c|c|}
\hline \multicolumn{3}{|c|}{ Надходження МЕА } & \multicolumn{3}{c|}{ Витрата МЕА } \\
\hline Компонент & кг/год & $\%$ & Компонент & кг/год & $\%$ \\
\hline 1 & 2 & 3 & 4 & 5 & 6 \\
\hline Розчин МЕА в т.ч. & 1143723,34 & 100 & Розчин МЕА в т.ч.: & 1193713,00 & 100 \\
\hline МЕА & 217740,26 & 19,038 & MEA & 217740,26 & 18,2406 \\
\hline $\mathrm{H}_{2} \mathrm{O}$ & 870961,04 & 76,151 & $\mathrm{H}_{2} \mathrm{O}$ & 870603,16 & 72,9324 \\
\hline $\mathrm{CO}_{2}$ & 54970,49 & 4,80628 & $\mathrm{CO}_{2}$ & 105229,23 & 8,8153 \\
\hline $\mathrm{H}_{2}$ & 12,46 & 0,00109 & $\mathrm{H}_{2}$ & 33,93 & 0,0028 \\
\hline
\end{tabular}


Продовження таблиці 5

\begin{tabular}{|c|r|r|r|r|r|}
\hline 1 & 2 & 3 & 4 & 5 & 6 \\
\hline $\mathrm{N}_{2}$ & 35,30 & 0,00309 & $\mathrm{~N}_{2}$ & 96,12 & 0,0081 \\
\hline $\mathrm{CO}$ & 1,41 & 0,00012 & $\mathrm{CO}$ & 3,85 & 0,00032 \\
\hline $\mathrm{Ar}$ & 1,58 & 0,00014 & $\mathrm{Ar}$ & 4,30 & 0,00036 \\
\hline $\mathrm{CH}_{4}$ & 0,79 & 0,00007 & $\mathrm{CH}_{4}$ & 2,15 & 0,00018 \\
\hline
\end{tabular}

Розрахунок теплового балансу абсорбції. Вихідні дані: температура тонко і грубо регенерованого розчину MEА на вході в абсорбер, відповідно, К: $\mathrm{T}_{\text {поч.1 }}=313, \mathrm{~T}_{\text {поч.2 }}=313 \mathrm{~K}$; тепловий ефект абсорбції: $\mathrm{Q}=1507$ кДж/кг $\mathrm{CO}_{2}$; середня теплоємність розчину MEA: $\mathrm{c}=4$ кДж/(кг.К); коефіцієнт втрат теплоти: 0,95 .

Температура розчину MEA на виході із стадії «тонкого» очищення, К:

$$
\begin{aligned}
& T_{\text {вих.1 }}=T_{\text {поч.1 }}+\frac{V\left(\mathrm{CO}_{2}\right)_{\text {поглин. }} \cdot 44 \cdot Q}{22,4 \cdot C \cdot m(M E A)_{p-\text { нут.p. }}} \cdot 0,95 . \\
& T_{\text {вих.1 }}=313+\frac{10158,33 \cdot 44 \cdot 1507}{22,4 \cdot 4 \cdot 561246,6} \cdot 0,95=325,7 .
\end{aligned}
$$

Пояснення: за даними таблиць 2 і 3 поглинається $\mathrm{CO}_{2}, \mathrm{M}^{3} /$ год:

$$
V\left(\mathrm{CO}_{2}\right)_{\text {поглин. }}=10175,33-17=10158,33 \text {. }
$$

Температура суміші розчинів $T_{6 x 2}$ на вході на стадію «грубого» очищення розраховується за правилом змішувача за витратами розчину після тонкого очищення і грубо регенерованого розчину з регенератора і дорівнює 319,5 К. Розрахунок температури розчину MEA зі стадії «грубого» очищення виконується аналогічно за вищенаведеною формулою і дорівнює 335,2 К, при цьому об'ємна витрата абсорбованого $\mathrm{CO}_{2}$ визначається за даними таблиць 1 і 2.

Кінетичний розрахунок абсорбера. В агрегаті синтезу аміаку потужністю 1360 т/добу працює двосекційний тарілчастий абсорбер. Розрахунок тарілчастого абсорбера зводиться до визначення кількості тарілок у верхній та нижній частинах абсорбера, що зрошуються тонко і грубо регенерованим розчином MEA, відповідно. Для цього виконується числове інтегрування виразу:

$$
N=\int_{P_{1}}^{P_{2}} \frac{d P}{P-P^{*}} \text {, де } \mathrm{P}-\text { робочий тиск } \mathrm{CO}_{2} \text {, }
$$

Па; $\mathrm{P}^{*}$ - рівноважний тиск, $\mathrm{CO}_{2}$, Па.

Верхня частина абсорбера. Вихідні дані. Тиск в абсорбері: $\mathrm{P}=2,8$ МПа. Концентрація $\mathrm{CO}_{2}$ : на виході з верхньої частини абсорбера
$\mathrm{C}_{\text {вих }}=0,01 \%$ об.; на вході у верхню частину абсорбера $\mathrm{C}_{\mathrm{Bx}}=\mathrm{c}\left(\mathrm{CO}_{2}\right)_{1}=5,64 \%$ об.; Ступінь карбонізації розчину МЕА: на вході у верхню частину абсорбера $\alpha_{1}=0,1$; на виході 3 верхньої частини абсорбера $\alpha_{2}=0,35$; Температуpa розчину MEA: на вході у верхню частину абсорбера $\mathrm{T}_{1}=313 \mathrm{~K}$; на виході 3 верхньої частини абсорбера $\mathrm{T}_{2}=325,7 \mathrm{~K}$; Кількість кроків інтегрування $\mathrm{n}=50$.

Алгоритм розрахунку. Парціальний тиск $\mathrm{CO}_{2}$ над розчином MEА у верхньому перерізі верхньої частини абсорбера, Па:

$P_{6}=P \cdot C_{\text {вux }} / 100 ; P_{6}=$

$=2,8 \cdot 10^{6} \cdot 0,01 / 100=280$.

Парціальний тиск $\mathrm{CO}_{2}$ над розчином MEA у нижньому перерізі верхньої частини абсорбера, Па:

$P_{H}=P \cdot C_{6 x} / 100 ; P_{H}=$

$=2,8 \cdot 10^{6} \cdot 5,64 / 100=157920$.

Крок інтегрування:

$d P=(P H-P B) / n=$

$=(157920-280) / 50=3152.8$

Зміна концентрації $\mathrm{CO}_{2}$ у газі на один крок інтегрування, \% об:

$d C=($ Cвx - Cвих $) / n=$

$=(5,64-0,01) / 50=0,113$.

Зміна ступеня карбонізації на один крок інтегрування:

$d \alpha=\left(\alpha_{2}-\alpha_{1}\right) / n=$

$=(0.35-0.1) / 50=0.005$.

Зміна температури розчину MEA на один крок інтегрування, $\mathrm{K}$ :

$d T=\left(T_{2}-T_{1}\right) / n=$

$=(325.7-313) / 50=0.2545$.

Концентрація $\mathrm{CO}_{2}$ у конвертованому газі, \% об.: $C_{i}=C_{i-1}+d C$.

Температура розчину MEA, К: $T_{i}=T_{i-1}+d T$.

Ступінь карбонізації розчину МЕА: $\alpha_{i}=\alpha_{i-1}+d \alpha$. 
Рівноважний тиск $\mathrm{CO}_{2}$ над розчином MEA при $\alpha<0,5$ розраховують за нашим апроксимаційним рівнянням довідкових даних [10], Па:

$$
P_{1 i}=10^{3} \cdot e^{\left(34.68+2.682925 \cdot \ln \alpha_{i}-0.0422613 \cdot C_{M E A}-10672.8 / T_{i}\right)} ;
$$

Парціальний тиск $\mathrm{CO}_{2}$ у конвертованому газі, Па: $P_{\mu i}=P_{\mu i-1}+d P$.

Необхідна кількість тарілок на один крок інтегрування: $N_{i}=d P /\left(P_{\mu i}-P_{1 i}\right)$.

Теоретична кількість тарілок для верхньої частини абсорбера: $N_{\text {mеор }}=\Sigma N i$.

Реалізація алгоритму представлена у таблиці 6. Враховуючи ККД тарілки $\eta_{\text {т }}=0,5$, необхідна кількість тарілок:

$\mathrm{N} 1=\mathrm{N}_{\text {теор }} / 0,5=8,73$.

Нижня частина абсорбера. Вихідні да$н i$. Тиск в абсорбері: $\mathrm{P}=2,8$ МПа. Концентрація $\mathrm{CO}_{2}$ : на виході 3 нижньої частини абсорбера $\mathrm{C}_{\text {вих }}=\mathrm{c}\left(\mathrm{CO}_{2}\right)_{1}=5,64 \%$ об.; на вході у нижню частину абсорбера
$\mathrm{C}_{\mathrm{Bx}}=\mathrm{c}\left(\mathrm{CO}_{2}\right)=17,36$ \% об.; ступінь карбонізації розчину MEA: на вході у нижню частину абсорбера $\alpha_{1}=0,35$; на виході 3 нижньої частини абсорбера $\alpha_{2}=0,67$. Температура розчину MEA: на вході у нижню частину абсорбера $\mathrm{T}_{1}=319,5 \mathrm{~K}$; на виході 3 нижньої частини абсорбера $\mathrm{T}_{2}=335,2 \mathrm{~K}$. Кількість кроків інтегрування $\mathrm{n}=50$.

Алгоритм розрахунку аналогічний раніше наведеному. Рівноважний тиск $\mathrm{CO}_{2}$ над розчином MЕА в цій частині абсорбера (використовується функція Если). Па:

при $\alpha<0,5$, Па:

$P_{1 i}=10^{3} \cdot e^{\left(34.68+2.682925 \cdot \ln \alpha_{i}-0.0422613 \cdot C_{M E A}-10672.8 / T_{i}\right)} ;$

при $\alpha>0,5$, Па:

$P_{1 i}=10^{3} \cdot e^{\left(22,44509+8,577414 \cdot \ln \alpha_{i}+0.0800379 \cdot C_{\text {MEA }}-5117,64 / T_{i}\right)}$.

Реалізація алгоритму представлена у таблиці 7. Враховуючи ККД тарілки $\eta_{\mathrm{T}}=0,5$, необхідна кількість тарілок:

$\mathrm{N} 2=\mathrm{Ni}_{\text {теор }} / 0,5=2,41$

Таблиця 6 - Розрахунок кількості тарілок верхньої частини абсорбера (фрагмент)

\begin{tabular}{|c|c|c|c|c|c|c|}
\hline № & $\alpha_{\mathrm{i}}$ & $\mathrm{T}_{\mathrm{i}}$ & $\mathrm{P}_{\mathrm{i}}$ & $\mathrm{C}_{\mathrm{i}}$ & $\mathrm{P}_{\mathrm{H}_{\mathrm{i}}}$ & $\mathrm{N}_{\mathrm{i}}$ \\
\hline 1 & 0,105 & 313,254 & 1,868 & 0,123 & 3432,800 & 0,919 \\
\hline 2 & 0,110 & 313,509 & 2,176 & 0,235 & 6585,600 & 0,479 \\
\hline 3 & 0,115 & 313,763 & 2,520 & 0,348 & 9738,400 & 0,324 \\
\hline 48 & 0,340 & 325,216 & 153,020 & 5,415 & 151614,400 & 0,021 \\
\hline 49 & 0,345 & 325,470 & 163,268 & 5,527 & 154767,200 & 0,020 \\
\hline 50 & 0,350 & 325,725 & 174,098 & 5,640 & 157920,000 & 0,020 \\
\hline & & & & & $\mathrm{N}_{\text {meop }}=\Sigma \mathrm{N}_{\mathrm{i}}=$ & 4,365 \\
\hline
\end{tabular}

Таблиця 7 - Розрахунок кількості тарілок нижньої частини абсорбера (фрагмент)

\begin{tabular}{|c|c|c|c|c|c|c|}
\hline № & $\alpha_{\mathrm{i}}$ & $\mathrm{T}_{\mathrm{i}}$ & $\mathrm{P}_{\mathrm{i}}$ & $\mathrm{C}_{\mathrm{i}}$ & $\mathrm{PH}_{\mathrm{i}}$ & $\mathrm{Ni}_{\text {meop }}$ \\
\hline 1 & 0,356 & 319,781 & 99,410 & 5,874 & 164483,200 & 0,040 \\
\hline 2 & 0,363 & 320,096 & 107,749 & 6,109 & 171046,400 & 0,038 \\
\hline 3 & 0,369 & 320,411 & 116,682 & 6,343 & 177609,600 & 0,037 \\
\hline 48 & 0,657 & 334,566 & 172134,344 & 16,891 & 472953,600 & 0,022 \\
\hline 49 & 0,664 & 334,880 & 189761,582 & 17,126 & 479516,800 & 0,023 \\
\hline 50 & 0,670 & 335,195 & 209021,442 & 17,360 & 486080,000 & 0,024 \\
\hline & & & & & $\mathrm{N}_{\text {meop }}=\Sigma \mathrm{N}_{\mathrm{i}}=$ & 1,207 \\
\hline
\end{tabular}

Загальна необхідна кількість тарілок в абсорбері:

$$
\mathrm{N}=\mathrm{N} 1+\mathrm{N} 2=8,73+2,41=11,14 \text {. }
$$

У промисловому абсорбері кількість тарілок дорівнює 15 [4], що свідчить про достовірність алгоритму розрахунку.
Висновки. Запропонований алгоритм матеріального, теплового та конструктивного розрахунків може бути використаний для аналізу роботи діючих виробництв, а також буде корисним для студентів при навчальному проектуванні процесу очищення технологічного газу. 


\section{Список літератури}

[1] Т. А. Семенова, Очистка технологических газов / под ред. Т. А. Семеновой. Москва: Химия, 1977.

[2] Ralph H. Weiland, Nathan A. Hatcher, and Jaime L. Nava, Post-combustion $\mathrm{CO}_{2}$ capture with amino-acid salts [Online]: Optimized Gas Treating, Inc. Clarita, OK 74535, USA. Available: https://www. protreat.com/files/publications/43/Manuscri pt_CO2_Capture_with_Amino_Acids.pdf

[3] Аминовая очистка. Россия, 2017 [Электронный ресурс]. Режим доступа: http://gazsurf.com/ru/gazopererabotka/oboru dovanie/modelnyj-ryad/item/aminovayaochistka

[4] А. Л. Концевой, Т. О. Лук'янчук, та С. А. Концевой, "Моделювання очищення газу від оксиду карбону (IV) розчином метилдіетаноламіну". Інтернаука: міжнар. наук. журн., № 15 (55), с. 28-32, 2018.

[5] А. Л. Концевой, Т. О. Лук'янчук, та С. А. Концевой, "Моделювання регенерації розчину метилдіетаноламіну". Інтернаука: міжнар. наук. журн., № 16 (56), c. 32-36, 2018

[6] Э. Г. Вакк, Г. В. Шуклин, и И. Л. Лейтес, Получение технологического газа для производства аммиака, метанола, водорода и высших углеводородов. Теоретические основы, технология, катализаторы, оборудование, системы управления. Москва, 2011.

[7] М. А. Янковський, I. М. Демиденко, Б. І. Мельников, О. Я. Лобойко, та Г. М. Корона, Технологія аміаку: навч. посіб. Дніпропетровськ: УДХТУ, 2004.

[8] В. П. Семенов, Производство аммиака / под ред. В. П. Семенова. Москва: Химия, 1985.

[9] О.Я.Лобойко, Л. Л. Товажнянський, та I. О. Слабун, Методи розрахунків у технології неорганічних виробництв: Ч. 1. 3в'язаний азот: підручник / за ред. О. Я. Лобойко та Л. Л. Товажнянського. Харків: НТУ ХПІ, 2001.

[10] Справочник азотчика: Физикохимические свойства газов и жидкостей. Производство технологических газов.
Очистка технологических газов. Синтез аммиака. 2 изд., перераб. Москва: Химия, 1986.

\section{References}

[1] T. A. Semenova, Process gas purification. Moscow: Himiya, 1977 [in Russian].

[2] Ralph H. Weiland, Nathan A. Hatcher, and Jaime L. Nava, Post-combustion $\mathrm{CO}_{2}$ capture with amino-acid salts [Online]: Optimized Gas Treating, Inc. Clarita, OK 74535, USA. Available: https://www.protreat.com/ files/publications/43/Manuscript_CO2_Capt ure_with_Amino_Acids.pdf

[3] Amine purification. Russia, 2017. [Online]. Available: http://gazsurf.com/ru/ gazopererabotka/oborudovanie/modelnyjryad/item/aminovaya-ochistka [in Russian].

[4] A. L. Kontsevoi, T. O. Lukianchuk, and S. A Kontsevoi, "Modeling of gas purification from carbon oxide (IV) by methyldiethanolamine solution". Internauka: Internat. sci. journ., no. 15 (55), pp. 28-32, 2018 [in Ukrainian].

[5] A. L. Kontsevoi, T. O. Lukianchuk, and S. A. Kontsevoi, "Modeling of methyldiethanolamine solution regeneration". Internauka: Internat. sci. journ., no. 16 (56), pp. 32-36, 2018 [in Ukrainian].

[6] E. G. Vakk, G. V. Shuklin, and I. L. Leytes. Obtaining of process gas for the production of ammonia, methanol, hydrogen and higher hydrocarbons. Theoretical fundamentals, technology, catalysts, equipment, control systems: textbook. Moscow, 2011 [in Russian].

[7] M. A. Yankovskyi, I. M. Demydenko, B. I. Melnykov, O. Ia. Loboiko, and H. M. Korona, Ammonia technology: textbook. Dnipropetrovsk: UDKhTU, 2004 [in Ukrainian].

[8] V. P. Semenov, Ammonia production. Moscow: Himiya, 1985 [in Russian].

[9] O. Ya. Loboiko, L. L. Tovazhnianskyi, and I. O. Slabun, Calculation methods in inorganic matter technology: Part 1. Fixed nitrogen: textbook. Kharkiv: NTU KhPI, 2001 [in Ukrainian].

[10] Reference book for nitrogen specialists: physical and chemical properties of gases and liquids. Process gas production. Processl gas estimation. Ammonia synthesis, 2nd ed., Moscow: Himiya, 1986 [in Russian]. 
A. L. Kontsevoi, Ph. D., associate professor, e-mail: kontsev@xtf.kpi.ua

S. A. Kontsevoi, Ph. D., associate professor e-mail: serkon157@ukr.net Igor Sikorsky Kyiv Polytechnic Institute Peremogy ave., 37, Kyiv, 03056, Ukraine

\section{MODELING OF TWO-FLOW GAS PURIFICATION FROM CARBON MONOXIDE (IV) BY MONOETHANOLAMINE SOLUTION}

A two-flow scheme for gas purification from $\mathrm{CO}_{2}$ by monoethanolamine (MEA) solution and by waste solution regeneration in two simultaneous recuperators is the object of the simulation, the productivity of ammonia is 1360 tons/day. Our algorithm takes into account the temperature fluctuations, component concentrations in gas and liquid phases at different points of the absorber.

The algorithm is implemented in Excel environment. The peculiarity of the calculation consists in the selection of $\mathrm{CO}_{2}$ concentration in the gas after "rough" purification to obtain approximately equal flows of finely and roughly recovered solutions in the absorber. For kinetic calculation of the absorber, the reference dependences of the equilibrium partial pressure of $\mathrm{CO}_{2}$ over the MEA solution are approximated, depending on the degree of carbonization, the temperature and $\mathrm{CO}_{2}$ concentration in the solution. The number of plates in two-section plate absorber is calculated by numerical integration.

The control calculation is performed with the following initial data. The consumption of converted gas supplied for purification is $206000 \mathrm{~m}^{3} /$ hour. The MEA temperature at the inlet is $313 \mathrm{~K}$. The concentration of the MEA at the inlet of the absorber - $20 \%$ by mass. The final concentration of $\mathrm{CO}_{2}$ is $0.01 \%$. The pressure in the absorber - 2.8 MPa. The concentration of the components in the dry gas mixture, \% vol.: $\mathrm{CO}_{2}-17.36$; $\mathrm{CO}-0.5 ; \mathrm{H}_{2}-61.64 ; \mathrm{CH}_{4}-0.3 ; \mathrm{N}_{2}-19.95 ; \mathrm{Ar}-0.25$.

The concentration of $\mathrm{CO}_{2}$ at the outlet, \% vol.: after "rough" purification was unknown and is selected by multivariate calculation - 5.64; after "fine" purification is 0.01 .

This algorithm can be used to analyze the performance of existing plants, and will also be useful for students' learning the design of process gas purification schemes.

Keywords: process gas, carbon oxide (IV), monoethanolamine, kinetics and thermodynamics of absorption, plate absorber.

Стаття надійшла 12.08.2019

Прийнято 12.09.2019 